\title{
Freire como pedagogo intercultural: diálogo, alteridad y lectura crítica del mundo
}

Freire as an intercultural pedagogue: dialogue, alterity and critical literacy of the world

Eduardo S. Vila Merino

e-mail: eduardo@,uma.es

Universidad de Málaga, España

J. Eduardo Sierra Nieto

e-mail: esierra@uma.es

Universidad de Málaga, España

Victoria E. Álvarez Jiménez

e-mail: victoria jimenez@hotmail.com

Universidad de Málaga, España

\section{Resumen}

La persona y la obra de Freire han fascinado e inspirado en los últimos 50 años a varias generaciones de educadoras y educadores de todo el planeta. A propósito del centenario de su nacimiento, nos planteamos volver a dialogar con su pensamiento reconociendo a nuestro autor como pedagogo intercultural. En este sentido, el artículo repasa distintas aportaciones a propósito de la sensibilidad intercultural de Freire para, a continuación, desarrollar con más detalle algunos aspectos del pensamiento freireano vinculados con esa dimensión. El artículo finaliza recuperando la consigna freireana de la lectura de la palabra y del mundo, enfocándonos en las relaciones de alteridad desde el prisma intercultural.

Palabras clave: educación intercultural; alteridad; teoría de la educación; relaciones de poder; alfabetización crítica.

\section{Abstract}

Over the past fifty years, Freire's person and work have fascinated and inspired several generations of teacher educators around the world. On the occasion of the centenary of his birth, we aim to generate dialogues alongside his thoughts and viewpoints, recognizing Freire as an intercultural pedagogue. The current article looks over diverse contributions that honor Freire's intercultural sensitivity. From there, we move into detailed and comprehensive aspects of the Freirean theory that relay the intercultural sensitivity. The article concludes by bringing back the Freirean motto around dialogue and critical literacy of the world. Moreover, it also focuses on the relations of otherness from an intercultural view.

Keywords: intercultural education; otherness; theory of education; power relationships; critical literacy.

Recibido / Received: 15-01-2021

Aceptado / Accepted: 02-06-2021

Publicación en línea / Published online: 28-07-2021

Cómo referenciar este artículo / How to reference this article:

Vila, E. S., Sierra, J. E. \& Álvarez, V. (2021). Freire como pedagogo intercultural: diálogo, alteridad y lectura crítica del mundo. Tendencias Pedagógicas, 38, pp. 46-56. doi: 10.15366.tp2021.38.005. 


\title{
1. Introducción
}

Decía Unamuno (2005) que «Los místicos medievales (...) distinguen entre lux, luz, y lumen, lumbre. La luz queda en sí, la lumbre es la que se comunica. Y un hombre puede lucir —y lucirse-, alumbrar —y alumbrarse» (p. 224). Freire era de los que alumbraban y, más que lucirse, ha iluminado a varias generaciones de educadoras y educadores. Y lo ha hecho teniendo como referente más importante un sólido armazón teórico, un corpus de conocimiento pedagógico basado en el rigor y la coherencia epistemológica y axiológica. No fue un mero creador de recursos metodológicos, sino de una manera de entender la educación desde su potencial emancipador, a favor de la justicia social y la convivencia en contextos cada vez más multiculturales, llenos de complejidad y desigualdades.

Precisamente contaba Henry Giroux en una reciente entrevista (França, 2019) que leer Pedagogía del oprimido cuando era profesor de secundaria al comienzo de su carrera le cambió la vida:

[...] me dio un lenguaje que permitía entender la educación como un proceso político. Es un libro que cambió la concepción sobre qué significa trabajar con personas a las que normalmente se considera «sin voz», y permitió entender que tienen una voz y se pueden narrar a sí mismas.

En esas mismas líneas, comentaba que dicha lectura le permitió disponer de herramientas en un momento en el que «[...] no podía darle una respuesta teórica sobre lo que estaba experimentando desde el punto de vista pedagógico». Posteriormente, Giroux tuvo el privilegio de trabajar con Paulo Freire durante quince años. Y ese encuentro, esa fascinación, esa inspiración con el libro, con el texto, y con la persona, se ha repetido en los últimos 50 años por parte de educadoras y educadores de todo el planeta.

Además de repetir el recurrente dato de que Freire es el autor más citado en educación en el mundo (443.025 citas en Google Académico en el momento de cerrar la escritura de este artículo), diremos — una vez más - que se trata de uno de los más importantes pedagogos del siglo XX. Todo un clásico al que hay que volver una y otra vez, justamente porque las grandes teorías nos inspiran, ofreciéndonos la posibilidad de tensionar el presente. Obras y autores que difícilmente ven agotada su capacidad de interpelarnos... si sabemos relacionarnos con ellas de manera fructífera. De un modo particular, Freire nos otorga un lugar privilegiado para repensar la educación desde la perspectiva intercultural, una dimensión que atraviesa todo su discurso pedagógico. A eso queremos dedicar este artículo.

\section{Repensar la educación intercultural con Freire}

En las primeras líneas de la Pedagogía del Oprimido, Freire (2002) escribía lo siguiente:

\begin{abstract}
Una vez más los hombres, desafiados por la dramaticidad de la hora actual, se proponen a sí mismos como problema. Descubren qué poco saben de sí, de su "puesto en el cosmos», y se preocupan por saber más. Por lo demás, en el reconocimiento de su poco saber de sí radica una de las razones de esa búsqueda, instalándose en el trágico descubrimiento de su poco saber de sí, hacen de sí mismos un problema. Indagan. Responden y sus respuestas los conducen a nuevas preguntas. (p. 37)
\end{abstract}

La dramaticidad del ahora es una cuestión lábil, condicionada y marcada por la siempre contradictoria acción humana en el cosmos. Pero más allá de su contenido, de su concreción histórica, el desafío que propone nuestro autor con estas líneas es el de no quedarnos atrapados en el fatalismo, la complacencia o la equidistancia.

Ser humanos, según el pensamiento freireano, consistirá en tomar partida, esforzándonos en ir siempre un poco más allá. De modo que cada nueva generación, que cada nuevo ser humano que llega al mundo, tenga la posibilidad de hacerse de manera original las preguntas acerca del sentido y la dirección, tanto de su vida singular como de la vida en común. Un horizonte teleológico en el que despunta el carácter contingente de la historia y, con éste, el carácter inacabado de la construcción personal y social. 
Uno de los ángulos desde donde enfocar la mencionada dramaticidad del ahora guarda relación con el tejido multicultural con el que se traman nuestras sociedades. Que vivimos en sociedades multiculturales constituye un hecho histórico e irreversible; como lo es el que la diversidad cultural continúa entrañando, tristemente, situaciones de profunda desigualdad. De ahí que su abordaje suponga uno de los más importantes desafíos que tenemos como sociedad ${ }^{1}$.

Freire (2006) fue muy consciente de ello toda su vida, pues sus inquietudes siempre partieron de una especial sensibilidad hacia el otro y la otra; hacia esa alteridad cultural que nos constituye; hacia esa alteridad oprimida y para la que la educación supone su gran oportunidad de emancipación y liberación.

Queremos por eso preguntarnos acerca del valor de la obra de Freire de cara a abordar los temas cruciales del debate educativo contemporáneo y los problemas sociales más urgentes de nuestro tiempo. Entre ellos, como decimos, la gestión de la diversidad cultural en tanto que construcción de unas políticas y unas prácticas de convivencia democráticas. Y es que, como recoge Maviglia (2019), la pedagogía de Freire resulta ser «un tipo de educación intercultural que promueve la originalidad y autenticidad de la persona y la diversidad de los seres humanos» (p. 390) ${ }^{2}$. En este sentido, existen diversos trabajos anteriores que han buceado en la perspectiva intercultural de la obra de Freire y a los que es necesario aludir.

Como Verdeja y González (2018) han señalado, Freire puede y debe ser reivindicado como un precursor en la defensa de los valores educativos del diálogo intercultural, puesto que entiende que la escuela debe estar atenta a la identidad/es cultural/es del educando y reconocer los valores de la diversidad cultural y lingüística; al tiempo que debe ser capaz de analizar críticamente las problemáticas socioculturales del contexto del propio proceso educativo.

No olvidemos que para Freire $(1978,1984)$ la cultura supone la reflexión y acción del ser humano que trata de dar respuesta a las interpelaciones de la realidad social y sus circunstancias, incluyendo aquí la realidad material de las personas y las instituciones y la realidad histórica. Por este motivo, todos somos sujetos activos de la cultura, creadores del mundo, al comprenderlo y dinamizarlo. Desde esta aproximación, cultura para Freire es todo cuanto el ser humano ejecuta, frente a lo que le viene dado por naturaleza, además de la adquisición sistemática de la experiencia humana anterior; pero siempre de una manera crítica e histórica, donde la perspectiva intercultural debe suponer un referente casi ontológico.

En esta línea, Estupiñán y Agudelo (2009) proponen una noción con la que pensar este vector de la obra de Freire: la sensibilidad intercultural. Desde ella, entienden que:

el espacio de la interculturalidad, como proceso educativo, responde a la búsqueda del reconocimiento de las diferentes identidades sociales y culturales, a la consideración de que hay diversas formas de ver y de percibir el mundo y a la renovación de las prácticas pedagógicas que conduzcan a la inclusión de nuevos saberes y de nuevas prácticas culturales. (p. 27)

La cuestión de la identidad cultural es expuesta por los autores, en la estela de la obra de Freire, dada su permanente preocupación por las relaciones con los otros, desde un punto de vista dinámico y relacional, que escapa a versiones innatistas e inmovilistas de la vida humana. Esto es así porque las identidades culturales se tejen desde las diferencias, entendiéndolas como ejes de los encuentros humanos, como puertas a vínculos, comprensiones, distinciones, conflictos o imaginarios. Nuestro autor tenía muy presente esto y, en sus libros, las analogías y vínculos entre la construcción identitaria y los procesos educativos, desde múltiples ópticas, son recurrentes.

\footnotetext{
${ }^{1}$ La actual situación de pandemia está conllevando, entre otras ramificaciones, la aparición de discursos xenófobos que vinculan la proliferación de la COVID-19 con la inmigración (Sense Tòpics, 2020). Además, como está esforzándose en visibilizar Naciones Unidas (20 de junio de 2020), existe una vulnerabilidad manifiesta en grupos entre los que se encuentran las personas migrantes, exiliadas y desplazadas.

2 Traducción propia.
} 
Encontramos entonces una idea-fuerza que atraviesa su obra y que, de alguna manera, articula su pedagogía: el radical reconocimiento de la diversidad, de la singularidad que entraña cada vida humana. Un imperativo ético que Freire (2006) se preocupó por encomendar como un mandato a cada educador, a cada educadora. Y porque era una pedagogía, se trataba de un imperativo que debía declinarse, que debía cobrar forma en el espacio de intercambio que es toda relación educativa (Vila, 2019).

Desde ese compromiso manifiesto y amoroso ha de nacer la vocación de cada educador para reconocer y ponerse del lado del estudiante. «Si no amo al mundo, si no amo la vida, si no amo a los hombres, no me es posible el diálogo», escribía precisamente Freire (2002, p. 107). Algo que difícilmente ocurrirá si el educador persiste en su creencia de que la suya es una posición epistemológica y culturalmente superior. Por eso sus mayores enemigos son el etnocentrismo y, también, el clasismo, en su sentido amplio: ese vector entrelazado en el que el opresor (como el oprimido) puede ser portador de una visión del mundo difícilmente auto-analítica. Justo lo contrario de lo que implica el eros pedagógico sobre el que ha escrito Kohan (2019), recuperando las últimas palabras de la Pedagogía del Oprimido para continuar su reflexión:

Si nada queda de estas páginas, esperamos que por lo menos algo permanezca: nuestra confianza en el pueblo. Nuestra fe en los hombres y en la creación de un mundo en el que sea menos difícil amar. (Freire, 2002, p. 243)

Esta es la esencia del pensamiento pedagógico freireano, y también «su fuerza política innegociable, irrenunciable: el capitalismo es inaceptable por muchas razones; la principal de ellas es la forma como hace imposible amar de verdad.» (Kohan, 2019, p. 123)

Llevando esto a un terreno pedagógico de proximidad, Estupiñán y Agudelo (2009) se preguntan «¿Cuáles son las relaciones entre la identidad cultural de los sujetos de la educación y la práctica educativa?» (p. 32). Y se responden apuntando en la dirección de la identidad como permanente proceso de construcción subjetiva en una relación dialéctica con el mundo y con los otros. Una relación sostenida y atravesada por el lenguaje.

En el horizonte de lo educativo estará, por tanto, la libertad como posibilidad, pero también como tensión: entre lo dado y lo adquirido, entre lo heredado y el acto mismo de heredar, entre los poderes instituidos (con sus políticas y sus tramas discursivas que cogeneran sentido de lo real) y su problematización. Luego hacen la pregunta más concreta: «¿qué es lo que sucede, frente a la identidad cultural dentro del contexto de la escuela? ¿Cuál es esa relación cultural entre el educador y el educando que debe orientar todo proceso educativo?» (p. 34)

Recalcan (Estupiñán y Agudelo, 2009) que solemos pensar en Freire como un educador popular, de adultos y de calle, pero hay escritos como los contenidos en Pedagogía de la autonomía y en Cartas a quien pretende enseñar que hablan de la escuela y del educador en ella. Un espacio cultural plural, complejo, de realidades entrelazadas. Un espacio político, de convivencia, social, interseccional. Un espacio pedagógico, simbólico, relacional, donde las discontinuidades y las convergencias construyen sentido, comunidad y conocimiento.

Será ese encuentro entre sujetos, esa relación que Freire alumbró y que se encargó de personificar, el territorio en el que se producen los encuentros interculturales como encuentros comunicativos (Vila, Martín y Sierra, 2014) y de recreación de saberes. Idea esta última que apunta a otro de los planteamientos centrales en la obra de Freire: la reivindicación de los saberes de los educandos, fundamentalmente como parte de la denuncia de la colonización cultural en tantos estados y comunidades. Un planteamiento que podemos reconocer también en otras tradiciones pedagógicas, como la defensa de la cultura de la infancia que auspiciaron Gianni Rodari o Loris Malaguzzi, entre otros.

En esa corriente pedagógica que reconoce a los niños y a las niñas (en Freire, al educando en un sentido amplio) como portadores y cocreadores de cultura, está inscrita otra idea emparentada con Freire: la humildad para escuchar al otro, a la otra, reconociendo en él o en ella otras fuentes de saber y de sentido. Así lo recogía él mismo: «No hay, por otro lado, diálogo si no hay humildad [...]. El diálogo, como encuentro de los hombres para la tarea común de saber y actuar se rompe si sus polos (o uno de ellos) pierde la humildad» (Freire, 2002, p. 107).

Este humanismo inscrito en la obra y la persona de Freire se dejaba ver no como una virtud moral, dice Kohan (2019), sino con 
una relación abierta, flexible y crítica respecto de los propios saberes. Es una especie de humildad socrática. En cuanto educador, ser humilde es una exigencia para todos aquellos que se respetan a sí mismos y a los educadores como sujetos legítimos y al mismo falibles, limitados e inciertos de conocimiento. Es una condición que permite escuchar a cualquiera en la medida en que todo el mundo sabe e ignora algo. Es una forma de humildad entre iguales, incompletos, seres deseosos de ser y de conocer más. (p. 123)

A modo de síntesis en este apartado, nos queremos apoyar en el trabajo de Verdeja y González (2018) quienes, a partir de la revisión teórica de parte de la obra de Freire, acaban formulando una serie de principios pedagógicos que traban el ideal de escuela inclusiva con la pedagogía intercultural de inspiración freireana:

- Un modelo de escuela intercultural es una escuela permanentemente abierta al cambio y a la mejora.

- Requiere operar en términos de humanidad y superar los etnocentrismos más primarios.

- Demanda replantear el modelo de formación y organización del profesorado, para que sea sensible a otras culturas y pueda valorar y enseñar la lengua materna de los estudiantes.

- Implica un proyecto pedagógico claramente orientado a favorecer la justicia social.

- Ha de contemplar un sistema de evaluación crítica y orientada a la mejora de la propia práctica docente.

- Implica la necesidad de reflexionar acerca de las injusticias y el sufrimiento (inmigración, pobreza, violencia contra las mujeres, etc.).

- Ha de estar abierta a la comunidad educativa y debe favorecer mecanismos de participación de profesorado, alumnado, familias y colectivos sociales.

- Debe estar abierto a la realidad contextual de los educandos.

- Conlleva necesariamente trabajar con diversidad de fuentes y recursos, y que el alumnado sea protagonista del proceso de enseñanza-aprendizaje.

- Conlleva, también, revisar la selección cultural de los contenidos que conforman el currículo común para hacerlo más universal y representativo de las culturas y de la realidad social.

- Debe favorecer que se produzcan procesos de comunicación dialógica que puedan modificar, en su caso, ideas erróneas o preconcebidas.

\section{Conocimiento educativo e interculturalidad}

Como sostiene Maviglia (2019), la pedagogía freireana y el enfoque intercultural se entrelazan en tanto que comparten una vocación respecto del reconocimiento de las singularidades y hacia una convivencia pacífica. Ya en la Pedagogía del oprimido (aunque nos atreveríamos a decir que en toda la obra de Freire) sobresale un radical reconocimiento de lo que cada uno y cada una trae consigo al mundo; y, con ello, aparece la cuestión de la responsabilidad y el compromiso del educador desde la perspectiva intercultural (Sierra, Caparrós, Vila y Martín, 2017; Vila, 2005 y 2011; Martín y Vila, 2007).

Una noción, la de los educadores como intelectuales comprometidos con la transformación, que nos puede parecer anacrónica por momentos pero que, sin embargo, convendría recuperar para así reactivar la discusión sobre el sentido de la educación y el lugar de los educadores en un mundo donde la ideología de la innovación parece haber fagocitado el sentido del oficio (Laval, 2004; Sierra et al, 2019). Y aunque la obra de Freire cristalizó en gran medida en lo que conocemos como pedagogía crítica, su notable influencia en la década de los 90 ha ido cediendo el paso ante el ascenso, como decimos, de una ideología de la innovación cuyos efectos en la subjetivación docente están perforando el sentido político y culturalmente fuerte de la función docente. Desde esa perspectiva, y a partir de los referentes anteriores, desarrollaremos ahora con más detalle algunos aspectos del pensamiento freireano vinculados con la dimensión intercultural.

Como hemos ido comentando, lo que pretendía el de Recife era articular un lenguaje crítico para que los educadores y educadoras analizásemos y desarrollásemos nuestro discurso y nuestra acción (praxis) como una forma de política cultural y de contestación ideológica, promoviendo una lectura crítica del mundo que es necesario trasladar a los educandos a través de una educación liberadora. 
Perspectiva que nos debe permitir analizar y comprender la relación dialéctica existente entre estructura social y acción humana, ya que los seres humanos no somos considerados entes pasivos de reproducción social, sino creadores de significados. En definitiva, sujetos con capacidad crítica y competencia comunicativa para la transformación social a través de prácticas que aspiren a ser emancipadoras.

De lo anterior se deduce, siguiendo a Giroux y McLaren (2001), con palabras de clara inspiración freireana, que

la relación entre teoría y práctica es multifacética y compleja. Algunos consideran la teoría simplemente conformando la práctica, mientras que en otros la práctica reestructura la teoría como una fuerza fundamental para el cambio. En algunos casos la teoría (en el más limitado sentido de la práctica de producción normativa y retórica) proporciona el refugio para pensar más allá de las actuales formas de práctica, tanto como para prever aquella que aún «no es». Privilegiar la práctica sin la debida consideración de las interacciones complejas que caracterizan la totalidad de las relaciones teoría/práctica y del lenguaje/significado no es simple reduccionismo, sino también una forma de tiranía teórica. Conformar la teoría de esta manera se convierte en una forma de práctica que ignora el valor político del «discurso teórico» dentro de una específica coyuntura histórica. (p. 158)

Esta visión dialéctica de la teoría y la práctica, y la puesta en valor del discurso político inherente a la misma hace que, bajo la tutela de Freire (1978), nos tengamos que hacer preguntas clave como las que siguen: «¿Qué se ha de saber? ¿Cómo se ha de saber? ¿En beneficio de quién y para qué? Además, ¿Contra qué o contra quién?» (p. 100).

Cuestiones que forman parte de una concepción pedagógica donde se resalta el valor de la categoría clase social como categoría cultural, como legítima y necesaria para seguir explicando dinámicas de la globalización neoliberal (Vila, 2011); una categoría complementaria con el discurso intercultural, en la medida en que este reivindica modos de acceder, comprender y aprehender conocimientos diversos y críticos. Así, la introducción en el análisis del elemento cultural, por tanto, enriquece la perspectiva social y ambos son imprescindibles en la construcción de teorías educativas críticas, sustantivamente interculturales desde la construcción teórica freireana.

Otro tema central en los referentes teóricos de Freire es el análisis del poder y, específicamente, de las relaciones de poder en el ámbito educativo. Esto se puede apreciar tanto en el discurso multicultural institucional que se queda en una concepción de fusión cultural (disolución, más bien) en aras de una cultura «nacional» común, como en el multiculturalismo liberal dominante, que «participa en el reconocimiento, la tolerancia y hasta en la celebración de las culturas marginadas» (McLaren y Farahmandpur, 2006, p. 137). Algo que tropieza con las ideas defendidas por Freire, ya que el multiculturalismo liberal habla del otro sin su «otredad», despojado de historia y contexto; mientras que Freire (1998) abogaba por la necesidad de ser en y desde los otros y otras, siendo el diálogo igualitario una exigencia ontológica.

En contra de este multiculturalismo liberal, que en la práctica ejerce como un multiculturalismo monocultural vinculado también a una suerte de capitalismo de control, Freire nos plantea construir un referente intercultural que conceptualiza en un marco relacional, mestizo y fronterizo de las identidades culturales, expresándose en aspectos como los siguientes:

- La interculturalidad formaría parte de una pedagogía de la diferencia que busca invertir las jerarquías de dominación y los axiomas de racionalidad occidentales hacia un desplazamiento de sus efectos políticos opresivos, en la línea de lo expuesto por Sousa Santos desde su «ecología de saberes» (2017). El conflicto aquí para Freire no se describe como una lucha lineal entre los oprimidos y los opresores sino como una lucha por los espacios de ruptura hegemónica fuera de la cual pueden obtenerse nuevas posibilidades de democratización y construirse nuevas articulaciones de identidad.

- Freire tenía una concepción de la cultura como algo cambiante, dinámico y recíproco: compartido entre los individuos y grupos de personas, pero siempre desde el referente de la justicia social. Por eso aboga por una heterogeneidad cultural que une a las personas de diferentes clases, etnias y géneros, combatiendo la comercialización de los valores y las creencias de las culturas subordinadas en una sociedad dominada por el consumidor, al volverse a concentrar en los problemas relacionados con la desigualdad social y animar la formación de alianzas diversas y plurales. 
- McLaren, seguidor de Freire, también ponía nombre a parte del discurso del pedagogo brasileño al realizar afirmaciones como la siguiente:

El multiculturalismo crítico enfatiza las experiencias colectivas de las personas marginadas en el contexto de su activismo político y movilización social. (...) Como marco para el desarrollo de una praxis pedagógica, el multiculturalismo crítico abre los espacios sociales y políticos para que los oprimidos desafíen las distintas formas de opresión de clase, raza y género que son producidas y reproducidas por las relaciones sociales dominantes. (McLaren y Farahmandpur, 2006, p. 145)

- Por eso es importante destacar también una idea implícita en la pedagogía freireana: la necesidad de conjugar políticas de reconocimiento y de redistribución para hablar de una educación emancipadora e intercultural (en línea con el dualismo, perspectiva de Fraser). Esto recuerda también la relación con esa especie de nuevo imperativo categórico descrito por de Sousa Santos (2005), cuando afirma que «tenemos derecho a ser iguales cada vez que la diferencia nos inferioriza; tenemos derecho a ser diferentes cuando la igualdad nos descaracteriza» (p. 223).

- Lo anterior engarza, además, con el concepto de concientización. Término que Freire popularizó y que posee una honda significación intercultural y como forma radical de lucha contra el fatalismo en tanto que primer paso para la transformación social; pues la concientización «pasa por la toma de conciencia, pero la profundiza» (Freire, 2003, p. 69). Y esto es así porque «no hay nada fatalísticamente determinado en el mundo de la cultura» (ibíd. p. 70).

- Ante todo esto, como dijimos con anterioridad, Freire habla del amor y la humildad en tanto que cualidades fundamentales para todo educador o educadora. El amor como constitutivo del ser humano, una adhesión incondicional a la alteridad del otro y la otra. Un amor que el propio Freire ponía como centro de su pensamiento y su acción.

Todos los puntos anteriores plantean una redefinición del conocimiento educativo desde la heterogeneidad de perspectivas e identidades de los grupos más desaventajados y marginados, en un proceso de ir más allá de la mera integración o inclusión formal; desarrollando una profundización en las múltiples voces necesarias para producir conocimiento y el carácter contingente de las culturas en esta línea. Sintetizando todo lo anterior, y siguiendo esa estela de Freire, Kincheloe y Steinberg (2000) plantearon una taxonomía que concluye con una visión del multiculturalismo crítico que se expone a continuación para clarificar lo comentado:

1. Las representaciones de raza, clase, género y sexualidad se basan en las grandes luchas sociales complejas.

2. Un currículum multicultural es parte de un esfuerzo mayor para transformar las condiciones sociales, culturales y estructuras institucionales que generan esas representaciones y perpetuar la opresión.

3. Raza, clase, género y diferencias sexuales existen en el contexto de poder y privilegio.

4. A diferencia de posiciones liberales, pluralistas y conservadoras, la justicia en las sociedades occidentales ya existe y solo necesita ser distribuida más equitativamente.

5. La comunidad no se construye simplemente en el consenso, sino como Paulo Freire decía, por unidad en la diversidad. En una sociedad multiétnica que respeta pero no esencializa las diferencias, se pueden realizar grandes avances en el cultivo de un pensamiento crítico y razonamiento ético.

6. Una comunidad homogénea fundada en el consenso no puede ser capaz de criticar la injusticia y las prácticas de exclusión que la debilitan.

7. La reforma de la patología cultural a menudo se deriva del reconocimiento de las diferencias, de la interacción con personas que no padecen las mismas injusticias.

8. La educación multicultural se basa en la solidaridad en la diferencia: otorga a los grupos sociales suficiente respeto para escuchar sus puntos de vista y usarlos para considerar los valores sociales existentes; se da cuenta de que las vidas de las personas en grupos diferentes están relacionadas entre sí hasta el punto de que cada uno es responsable ante todos los demás.

9. Es esencial hacer el compromiso de la legitimación de múltiples tradiciones del conocimiento.

10. Los estudiantes vienen a ver sus propios puntos de vista como una de las muchas social e históricamente construidas formas de ver. 


\section{A modo de conclusión}

La educación como proceso de humanización tiene en su horizonte la cuestión de la libertad (Freire, 1997, 2005). Una libertad que es necesariamente solidaria y dialógica, donde el valor de la comunicación reside precisamente en la pluralidad y el respeto; en definitiva, en la ética como eje relacional que sostiene una visión de la alteridad como constitutiva del ser-en-el-mundo, puesto que, como el propio Freire (2001) sostenía:

La consciencia del mundo engendra la consciencia de mí mismo y de los otros en el mundo y con el mundo. Por eso la inserción en el mundo y no en la adaptación a él nos volvemos seres históricos y éticos, capaces de optar, de decidir, de abrirnos paso. (p. 100)

Bajo el prisma intercultural, y como hemos planteado a lo largo del artículo, el pensamiento de Freire nos invita a pensar entrelazadamente la cuestión de la identidad y la de la convivencia, esforzándonos en no quedar atrapados en las referencias identitarias. Y es que como nos recuerda Maglivia (2019), la educación como práctica de bumanización

es un medio para superar la identidad, los cierres y los prejuicios del sentido de pertenencia y abrirnos, en cambio, a nuevos horizontes de convivencia democrática. De ahí la necesidad de un camino pedagógico y un espacio educativo dedicado a desafiar «los prejuicios, los cánones cognitivos y axiológicos, llevándonos más allá de las identidades, sin negarlas, y hacia un universo ético construido sobre el encuentro y el diálogo. Una necesidad que conduce hacia un nuevo horizonte de vida, de relaciones, de intercambios en los que la regla es estar con los demás, ponerse de acuerdo y establecer espacios comunes que respeten las diferencias y su valor $\left.^{3}\right\rangle^{8}$. (p. 389)

Justamente, ese abrirnos a nuevos horizontes que recoge Maviglia, como el abrirnos paso de la anterior cita de Freire, remiten a un mismo fin al que estamos aludiendo a lo largo del artículo: el afán por dialogar con Freire a propósito de lo que sus planteamientos nos puedan enseñar hoy.

Décadas atrás, Freire impulsó distintos programas de alfabetización en lugares del mundo que se abrían, precisamente, a un horizonte de emancipación. El asunto era, nos recuerda Rodríguez (2021)

[...] cómo la enseñanza de la lectura debía convertirse en una herramienta para cambiar su propio mundo, para convertirlos en protagonistas y actores de su propia realidad, para escribir su propio relato comprendiendo cuál había sido su historia previa y cuál querían que fuera su futuro. (pp. 251-252)

Y aunque el propio Rodríguez nos advierte de las limitaciones de extrapolar un planteamiento como este, inscrito en unas circunstancias históricas muy concretas, al presente, no cabe duda de que la consigna freireana del «reading the word $\&$ the world» continúa siendo inspiradora en un sentido general, para la educación, y en un sentido particular, para la educación intercultural.

Cassany y Castellà (2010) nos recuerdan, desde su exposición sobre las relaciones entre literacidad y criticidad, que leer y escribir (lo que hoy concebimos como prácticas letradas) no son solo «procesos cognitivos o actos de (des)codificación, sino también tareas sociales, prácticas culturales enraizadas históricamente en una comunidad de hablantes» (p. 354). Y, en este sentido, apuntan a Freire como una de las figuras cruciales en el desarrollo de la lectura crítica.

Por su parte, Caride y Pose (2015) señalan que

Se lee para aprender, adquirir cultura, acceder críticamente al conocimiento, poder ubicarse en la sociedad y estar en disposición de entenderla para posicionarse en y ante el mundo como personas conscientes, autónomas, libres y responsables. (p. 67)

\footnotetext{
${ }^{3}$ Traducción propia.
} 
En esa misma línea, y como nos recuerda Morales (2018), la lectura crítica en Freire (1984) alcanza a ser una herramienta al servicio de la liberación del ser humano; un medio para escudriñar la realidad y ganar en capacidad para comprender el carácter socialmente construido de esta, así como para vislumbrar y construir posibles vías de transformación personal y colectiva desde el marco de los derechos humanos y la convivencia democrática. La lectura crítica se ha posicionado, continúa Morales (2018),

como una herramienta enfocada en promover el desarrollo de habilidades cognitivas que posicionan al hombre como sujeto histórico capaz de asumir postura desde la crítica y la reflexión de su entorno con el propósito de generar nuevas aportaciones que diversifiquen la comprensión del mundo. (p. 177)

Desde esta óptica, la educación cobra sentido y ser en la relación con el otro, en el hacernos cargo de él o ella, en acompañarle, en ayudarle; y esa alteridad que supone nos permite hacer visible la relación y sus consecuencias y connotaciones educativas (Vila, 2019). La pedagogía de Freire, en este sentido, constituye también una pedagogía de la alteridad que, por definición, se va construyendo permanentemente, ya que está precedida por una reflexión antropológica, ética y epistemológica que define su contexto, su compromiso y las experiencias que le dan sentido. Es desde ahí que su pensamiento nos interpela: desde la interrelación entre responsabilidad y alteridad, tan indisolublemente ligada a la interculturalidad.

En todo caso, no podemos olvidar que la relación de alteridad podemos circunscribirla desde lo ontológico, lo social y lo ético. En el primer caso, la mirada ética se da desde la presencia o la ausencia de un ser semejante; desde el reconocimiento, la afirmación recíproca, la valoración de su diferencia y el sentido de su identidad, tal y como es, sin condiciones ni excusas, sino como cómplice en ese proyecto común e intercultural que denominamos humanidad. Desde lo social hablaremos de una dimensión política e incluso normativa, en la medida en que el otro nos exige la dimensión colectiva de la ética al implicar también la presencia de un tercero. Y en el caso de la ética, evidentemente hay que hacer referencia a una relación de responsabilidad y complicidad, pero también a algo más, puesto que la alteridad no es solo una característica de lo ético, sino que construye su sentido y constituye su esencia.

Por todo ello, podemos estar de acuerdo en el hecho de que la respuesta pedagógica y didáctica a la llamada sociedad multicultural debe provenir de una profunda reflexión sobre la naturaleza de la diferencia humana y el origen social de las desigualdades que demandará un posicionamiento respetuoso con las culturas insertas en la misma, a la vez que intolerante con las premisas segregadoras. A su vez esa reflexión nos debe dar pistas en torno a la comprensión e interpretación de la realidad educativa y la configuración de los espacios de relaciones como espacios dialógicos, a la manera que indicó Freire; la (re)construcción crítica del universo de significados desde referentes éticos, así como sobre el reconocimiento del valor que para el aprendizaje de toda la comunidad educativa supone la pluralidad de cosmovisiones y formas de acceder e interpretar el conocimiento.

Para concluir, nos ha parecido significativo hacerlo con las últimas palabras que escribió Freire (2001) unos días antes de fallecer, como un gesto inspirado en su vida misma; en comprender la historicidad del ser humano, su carácter inconcluso, su presencia permanente, su consciencia intercultural, porque

Si nuestra opción es progresista, si estamos a favor de la vida y no de la muerte, de la equidad y no de la injusticia, del derecho y no de la arbitrariedad, de la convivencia con el diferente y no de su negación, no tenemos otro camino que vivir plenamente nuestra opción, encarnarla, disminuyendo así la distancia entre lo que hicimos y lo que hacemos. Despreciando a los débiles, engañando a los incautos, ofendiendo a la vida, explotando a los otros, discriminando al indio, al negro, a la mujer, no estaré ayudando a mis hijos a que sean serios, justos y amantes de la vida y de los demás... (p. 78)

\section{Referencias}

Caride, J. A. \& Pose, H. (2015). Leer el mundo hoy o cuando la lectura se convierte en diálogo. Ocnos, 14, pp. 65-80. doi: 10.18239/ocnos_2015.14.05.

Cassany, D. \& Castellà, J. M. (2010). Aproximación a la literacidad crítica. PERSPECTIVA, 28(2), 
pp. 353-374. doi: https://doi.org/10.5007/2175-795X.2010v28n2p353

De Sousa Santos, B. (2005). El milenio huérfano. Ensayos para una nueva cultura política. Madrid: Trotta.

De Sousa Santos, B. (2017). Justicia entre saberes. Epistemologias del Sur contra el epistemicidio. Madrid: Morata. doi: $10.2307 /$ j.ctvnp0k5d.4.

Estupiñán, N. \& Agudelo, N. (2009). La Sensibilidad Intercultural en Paulo Freire. Revista Historia de la Educación Latinoamericana, 13, pp. 85-100. Disponible en: https://revistas.uptc.edu.co/index.php/historia educacion latinamerican/article/view/1535/1531.

França, J. (2019). Entrevista a Henry Giroux. CCCBLAB. Investigación e Innovación en Cultura. Recuperado de: http://lab.cccb.org/es/henry-giroux-defender-que-la-educacion-tiene-que-serneutral-es-decir-que-nadie-debe-rendir-cuentas-de-ella/.

Freire, P. (1978). Pedagogía y acción liberadora. Bilbao: Zero.

Freire, P. (1984). La importancia de leer y el proceso de liberación. Buenos Aires: Siglo XXI.

Freire, P. (1997). A la sombra de este árbol. Barcelona: El Roure.

Freire, P. (1998). Pedagogía de la esperanza. Un reencuentro con la «Pedagogía del oprimido». México: Siglo XXI. (1a. ed. 1993)

Freire, P. (2001). Pedagogía de la indignación. Madrid: Morata.

Freire, P. (2002). Pedagogía del oprimido. Buenos Aires: Siglo XXI. (1a edición 1970)

Freire, P. (2003). El grito manso. Buenos Aires: Siglo XXI.

Freire, P. (2005). La educación como práctica de la libertad. Buenos Aires: Siglo XXI. (1a edición 1967)

Freire, P. (2006). Pedagogía de la autonomía. Madrid: Siglo XXI. (1a edición 1997)

Giroux, H. A. \& McLaren, P. (2001). Sociedad, cultura y educación. Buenos Aires: Miño y Dávila.

Kincheloe, J. \& Steinberg, S. (2000). Repensar el multiculturalismo. Barcelona: Octaedro.

Kohan (2019). Paulo Freire mas que nunca. Una biografia filosófica. CLACSO.

Laval, Ch. (2004). La escuela no es una empresa. Barcelona: Paidós.

Martín, V. M. \& Vila, E. S. (2007). Mapas de exclusión, animación sociocultural y espacios interculturales en la globalización. In X. M. Cid \& A. Peres. Educación social, animación sociocultural y desarrollo comunitario. SIPS: Congreso Iberoamericano de Pedagogía Social.

Maviglia, D. (2019). The Intercultural Perspective in Paulo Freire's Pedagogy of the Oppressed. Studi Sulla Formazione/Open Journal of Education, 22(2), pp. 387-395. https://oajournals.fupress.net/index.php/sf/article/view/10812

McLaren, P \& Farahmandpur, R. (2006). La enseñanza contra el capitalismo global y el nuevo imperialismo: una pedagogía crítica. Madrid: Popular.

Morales, J. (2018). Aportes de Paulo Freire a la Investigación y a la Lectura Crítica. Revista Internacional de Educación para la Justicia Social, 7(2), pp. 175-192. doi: https://doi.org/10.15366/riejs2018.7.2.010

Naciones Unidas (20 de junio 2020). La discriminación racial en el contexto de la crisis del covid-19. Oficina del Alto Comisionado. Recuperado de:

https://www.ohchr.org/Documents/Issues/Racism/COVID-19_and_Racial_Discrimination_ES.pdf.

Rodríguez, J. (2021). La furia de la lectura. Barcelona: Tusquets.

Sense Tòpics (2020). Racismo y xenofobia en tiempos de Covid. Discurso mediático y politico contra la migración durante la pandemia. Comisión de Ayuda al refugiado, País Valenciano. Disponible en:

https://sensetopics.org/wp-content/uploads/2020/12/INFORME-SENSE-TOPICS-2020-CASTELLANO.pdf.

Sierra, J. E., Caparrós, E., Vila, E. S. \& Martín, V. M. (2017). Hacia una ciudadanía democrática e intercultural. Apuntes para la formación del profesorado. Revista Publicaciones, 47, pp. 37-53. Disponible en: https://revistaseug.ugr.es/index.php/publicaciones/article/view/7196.

Sierra, J. E., Navas, M., Caparrós, E. \& Salarirche, N. (2019). «¿A qué llamamos innovación educativa? 5 ideas clave para la formación inicial del profesorado». In J. Gómez-Galán; Ma P. Cáceres-Reche; E. Delgado-Algarra (Eds.). Experiencias en innovación docente y aportes de investigación sobre la praxis universitaria (pp. 125-144). Barcelona: Octaedro.

Unamuno, M. (2005). Manuel de quijotismo. Cómo se hace una novela. Salamanca: Editorial de la Universidad de Salamanca.

Verdeja, Ma \& González, X. A. (2018). Aportaciones de Paulo Freire a la educación intercultural. Un estudio de caso en la Educación Secundaria Obligatoria. Revista Iberoamericana de Educación, 76, pp. 143-168. doi: https://doi.org/10.35362/rie7602854 
Vila, E. S. (2005). Mundo de la vida y cultura: la educación como acción ética e intercultural. Teoría de la Educación. Revista Interuniversitaria, 17, pp. 81-96. doi: https://doi.org/10.14201/3110

Vila, E. S. (2011). Buscando un lenguaje común en Educación: ¿De qué hablamos cuando hablamos de interculturalidad? DEDiCA, Revista De Educasãa E Humanidades, 1, pp. 147-158. doi: https://doi.org/10.30827/dreh.v0i1.7164

Vila, E. S., Martín, V. M. \& Sierra, J. E. (2014). «De la ética del discurso a la ética intercultural: reflexiones pedagógicas». In E. S. Vila, V. M. Martín, T. Castilla \& J. E. Sierra (Coords.). Ética, educación y convivencia. Fundamentos teórico-prácticos (pp. 25-40). Málaga: Aljibe.

Vila, E. S. (2019). Repensar la relación educativa desde la pedagogía de la alteridad. Teoría de la Educación, Revista Interuniversitaria, 31(2), pp. 177-196. doi: https://doi.org/10.14201/teri.20271 